\title{
Do soil aggregates really protect encapsulated organic matter against microbial decomposition?
}

\author{
Marc-O. Goebel, Susanne K. Woche \& Jörg Bachmann \\ Institute of Soil Science, Leibniz University of Hannover, Herrenhäuser Str. 2, D-30419 Hannover, Germany; e-mail: \\ goebel@ifbk.uni-hannover.de
}

\begin{abstract}
Soil aggregates can provide an effective protection of organic matter against microbial decomposition as reported by several macroaggregate disruption studies. However, research on the role of aggregation for carbon mineralization was mainly focused on arable soils. In the present study we aim to clarify the impact of aggregation on organic matter protection by measuring carbon mineralization in terms of microbial respiration rates of intact macroaggregates (2-4 and 4-8 mm) and corresponding crushed aggregates from seven topsoil horizons from both arable and forest sites. For two arable and one forest soil we found a significantly $(P<0.001)$ lower carbon mineralization from intact aggregates as compared to the corresponding crushed material. The portion of aggregate protected carbon reached up to $30 \%$ for a grassland soil. For the other arable and forest soils no significant effect of aggregation was found. Similarly, no clear trend could be found for the protective capacity of different size fractions. We conclude that protection by aggregation is effective primarily for soils with a large pool of labile organic matter regardless of their usage as arable land or forest.
\end{abstract}

Key words: microbial respiration; organic matter stabilization; soil aggregates

\section{Introduction}

Organic matter is crucial for a wide range of soil physical, chemical and biological properties and processes like the development and stability of aggregates, water retention, cation exchange and buffering capacity, storage and supply of nutrients (Stevenson, 1994). Stabilization processes that reduce the potential of soil organic matter (SOM) to become mineralized by microorganisms are therefore of great interest.

According to Sollins et al. (1996) one important stabilization mechanism results from the spatial inaccessibility of SOM when encapsulated in aggregates. Evidence that aggregation physically protects SOM from decomposition has been provided by various aggregate disruption studies (e.g. Elliott 1986; Gupta \& Germida 1988; Hassink 1992, Goebel et al. 2005). According to a model of Tisdall \& Oades (1982) microaggregates $(<250 \mu \mathrm{m})$ provide the greatest protection, whereas macroaggregates $(>250 \mu \mathrm{m})$ which are built up of microaggregates are less effective. The dynamics of SOM in aggregate fractions were found to be strongly related to the lifetime of the aggregates themselves (Besnard et al. 1996). Stable macroaggregates may exist only for a few years, but microaggregates may exist for decades (Puget et al. 2000).

Investigations of Puget et al. (1995) demonstrated that stable (slaking-resistant) macroaggregates are enriched in soil organic carbon (SOC), while increasing aggregate size was related to increasing SOC content
(Puget et al. 1999). Investigations of Chenu et al. (2001) showed that the protective effect of aggregation may also be influenced by the size of the primary particles forming the aggregates. In a sandy soil, microorganisms were present both on the surface and inside the aggregates, whereas they mainly were concentrated on the surface of clayey aggregates.

Most studies that found a positive impact of aggregation on SOM stabilization focused on arable soils. While these studies reported a protective effect of aggregation, John et al. (2005) found no evidence for a physical protection of SOM by aggregate formation. These authors emphasized that the higher stability of SOM occluded in aggregates may also be explained by a relative accumulation of more recalcitrant carbon compounds.

Thus, in the present study, we aim to clarify the impact of aggregation on SOM protection, tested for differently sized macroaggregates from different soil types of both arable and forest sites. Organic matter degradation was determined by respiration experiments that measured the $\mathrm{CO}_{2}$-release from intact aggregates and corresponding crushed aggregates.

\section{Material and methods}

Soil

We used topsoil material from three arable and three forest sites in Germany. Basic soil properties are given in Table 1. The texture of the arable soils ranged from silt loam to 
Table 1. Selected physical and chemical properties of the soils investigated.

\begin{tabular}{|c|c|c|c|c|c|c|c|c|}
\hline \multirow{2}{*}{ Site } & \multirow{2}{*}{ Soil type } & \multirow{2}{*}{ Variant/land use } & \multirow{2}{*}{ Horizon } & Sand & Silt & Clay & $\mathrm{SOC}$ & \multirow{2}{*}{$\mathrm{pH}^{a}$} \\
\hline & & & & & wt.- $\%$ & & $\mathrm{~g} \mathrm{~kg}^{-1}$ & \\
\hline \multirow{2}{*}{ Rotthalmünster } & \multirow{2}{*}{ Gleyic Luvisol } & Wheat $\left(\mathrm{NPK}^{b}\right)$ & Ap & 10.2 & 72.6 & 17.2 & 12.8 & 6.3 \\
\hline & & Grassland & $\mathrm{Ah}$ & 10.2 & 72.6 & 17.2 & 26.4 & 5.4 \\
\hline Halle & Chernozem & Rye (NPK) & Ap & 72.7 & 18.3 & 9.0 & 9.0 & 5.8 \\
\hline Banteln & Luvisol & Agricultural & $\mathrm{Ap}$ & 5.7 & 81.9 & 12.4 & 9.7 & 7.3 \\
\hline Steinkreuz & Dystric Cambisol & Forest (beech, oak) & $\mathrm{Ah}$ & 54.9 & 35.1 & 10.0 & 70.0 & 3.2 \\
\hline Waldstein & Haplic Podzol & Forest (spruce) & Aeh & 47.4 & 37.9 & 14.7 & 38.0 & 2.8 \\
\hline Chorin & Cambisol/Stagnic Gleysol & Forest (beech, oak, larch) & $\mathrm{Ah}$ & 67.5 & 25.1 & 7.4 & 37.9 & 3.7 \\
\hline
\end{tabular}

${ }^{a} \mathrm{pH}$ measured in $0.01 \mathrm{M} \mathrm{CaCl}_{2}$ solution; ${ }^{b} \mathrm{NPK}$ : fertilized with nitrogen, phosphorus and potassium.

sandy loam, the $\mathrm{pH}$ was neutral to slightly acidic with SOC contents ranging from 9.0 to $26.4 \mathrm{~g} \mathrm{~kg}^{-1}$. The acidic forest soils had a sandy loamy texture and SOC contents between 37.9 and $70.0 \mathrm{~g} \mathrm{~kg}^{-1}$. For detailed information about the sites we refer to Goebel et al. (2008).

For the incubation experiments field moist soil was sieved to 2-4 and 4-8 $\mathrm{mm}$, termed in the following as 'small' and 'large' aggregate fraction, respectively. One half of each aggregate fraction was gently crushed with a pistil in order to evaluate the effect of aggregation on soil respiration.

\section{Incubation experiments}

For the air-dried samples from Rotthalmünster (RTM) the initial water content was adjusted by equilibration at -40 $\mathrm{kPa}$ water potential which corresponded to initial water contents of 22.0 and $30.6 \mathrm{wt} . \%$ for the wheat and grassland variant, respectively. The initial water content of the Steinkreuz and Waldstein samples was adjusted to $21 \mathrm{wt} . \%$ by addition of deionized water. For the soils from Halle (9 wt.\%), Banteln (7.5 wt.\%) and Chorin (26 wt.\%) the original field water content was taken as initial condition.

Each sample was filled into a glass flask $(300 \mathrm{~mL})$ equipped with a septum at the top. To minimize evaporation losses from the soil each flask was supplied with a polyethylene reservoir filled with $10 \mathrm{~mL}$ deionized water. The reservoir was perforated to allow water vapor exchange with the sample. Gas aliquots of $5 \mathrm{~mL}$ were taken from the headspace of each incubation flask with a medical syringe. Usually, measurements were performed two times per week, whereas each incubation flask was sampled twice. To prevent inhibition effects due to $\mathrm{CO}_{2}$ accumulation, each incubation flask was aired after the measurements. The forest soils were incubated in duplicate (Waldstein and Steinkreuz) or triplicate (Chorin) to account for the larger heterogeneity of the material.

Release of $\mathrm{CO}_{2}$ was quantified by gas chromatography (Perkin Elmer, Auto System XL, TCD, Überlingen, Germany). The molar amount of $\mathrm{CO}_{2}$ was calculated using the ideal gas equation. From the initial SOC content and the loss of carbon after each time step the percentage of remaining carbon, $C_{\text {rem }}(\%)$,was calculated. Organic carbon content was measured by dry combustion and infrared detection of $\mathrm{CO}_{2}$ (CNS analyser, LECO, CNS-2000, Mönchengladbach, Germany).

A two-component first-order decay model with two different mineralization rates was fitted to the measured data (after Qualls \& Haines, 1992, modified):

$$
C_{\mathrm{rem}}=\left[(100-b) e^{-k_{1} t}\right]+\left[b e^{-k_{2} t}\right]
$$

where $t$ is the time $(\mathrm{d}),(100-b)$ and $b$ are the initial percentages of the rapidly (labile) and slowly decaying (stable) SOM pools (\%), respectively, and $k_{1}$ and $k_{2}$ are the mineralization rate constants of the two pools $\left(\mathrm{d}^{-1}\right)$. Half-lives of the pools (d) were calculated as $H L_{\mathrm{lab}}=\ln 2 / k_{1}$ and $H L_{\text {stab }}$ $=\ln 2 / k_{2}$, respectively.

The difference between the cumulative loss of carbon from the crushed samples, $C_{\min (\mathrm{C})}(\mathrm{mg})$, and the cumulative loss of carbon from the aggregates, $C_{\min (\mathrm{A})}(\mathrm{mg})$, was taken as the aggregate protected carbon. The amount of unprotected carbon corresponds to the loss of carbon from the aggregates, $C_{\min (\mathrm{A})}(\mathrm{mg})$. The percentage of aggregate protected carbon, $C_{\text {prot }}(\%)$, was calculated as:

$$
C_{\text {prot }}=\frac{\left(C_{\min (\mathrm{C})}-C_{\min (\mathrm{A})}\right) \times 100}{C_{\min (\mathrm{H})}}
$$

\section{Statistics}

To test the statistical significance of respiration rate differences one-way univariate ANOVA was calculated for aggregation and size as main effects using SPSS 10.0 (SPSS Inc., Chicago, USA). Statistical calculations were performed with the complete data set of all soils and for each soil separately. To eliminate the effect of incubation time ANOVA was performed with the inclusion of time as a covariate.

\section{Results}

\section{Mineralization rate constants and half-lives}

Figure 1 shows the percentage of remaining carbon, $C_{\text {rem }}$, as a function of time for the arable and forest soils. All soils showed two stages of carbon loss with incubation time. Generally, carbon loss was large at the beginning of the incubation and then decreased after a certain time to lower levels. The two stages of carbon loss can be described by the mineralization model of Qualls \& Haines (1992) with a labile and a stable pool and corresponding mineralization rate constants $k_{1}$ and $k_{2}$, respectively. The respective constants are given in Table 2.

Generally, the adjustment of the model was good with $R^{2}>0.920(P<0.001)$ for all soils. The mineralization rate constants of the labile pool were between $2.25 \times 10^{-2}$ and $3.50 \times 10^{-1} \mathrm{~d}^{-1}$ which correspond to half-lives between 2 and 31 days. The largest half-lives were determined for RTM, Halle and Chorin ( $>14$ days), whereas the half-lives of the other soils 

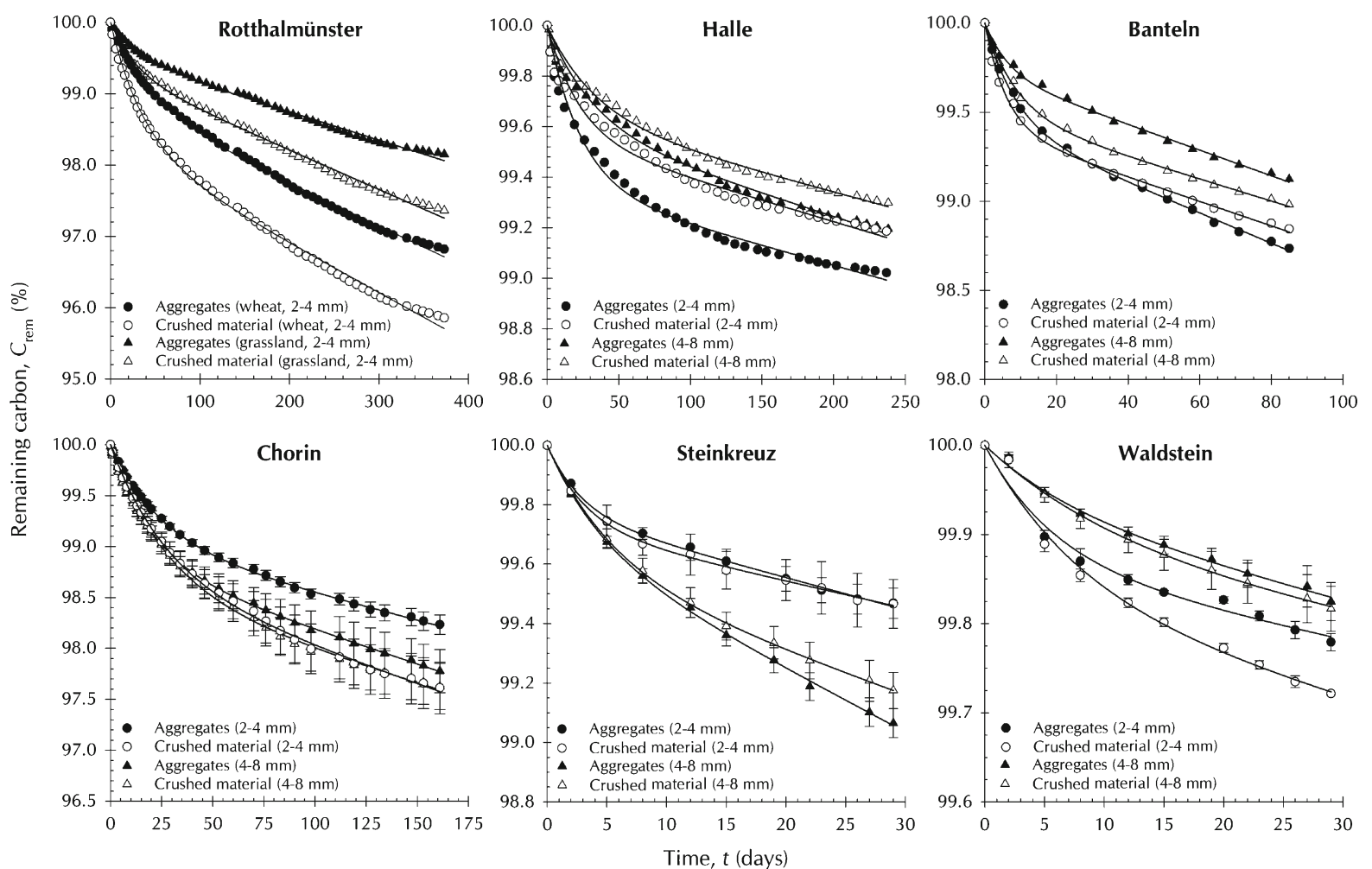

Fig. 1. Remaining carbon, $C_{\text {rem }}$, as a function of time, $t$, for intact aggregates and the corresponding crushed material.

were $<8$ days. The Halle soil showed markedly larger half-lives of the stable pool compared to the other soils. The portion of the labile pool was largest for RTM (wheat) and Chorin and smallest for Waldstein. The Steinkreuz soil showed the largest mineralization constants and consequently the smallest half-lives for both the labile and the stable pool. The results indicated a comparatively small labile pool which was mineralized rapidly for Steinkreuz and Waldstein and a comparatively large labile pool which was mineralized slowly for RTM (wheat) and Chorin.

For most soils, the mineralization rate constants and half-lives reflect the general behavior as shown in Fig. 1; however, there were some inconsistencies. Although cumulative carbon loss was larger for the crushed material of Waldstein (large fraction), mineralization rate constants of both pools indicated a more rapid carbon loss for the aggregates. Mineralization rate constants of Halle (small fraction) yielded smaller halflives of both pools for the crushed material indicating a slower carbon loss from the aggregates. However, Fig. 1 clearly shows that cumulative carbon release from the aggregates was larger. Obviously, for some soils the mineralization rate constants should be interpreted with caution.

For the small fraction of Waldstein the fitting revealed smaller half-lives for the stable pool but larger for the labile pool. Such non-uniform results with respect to the mineralization rate constants were found also for Chorin (both fractions) and Banteln (small fraction), where the crushed fractions showed smaller halflives for the labile pool but larger for the stable pool.
For Chorin and Banteln this may indicate that the labile pool plays a more important role in explaining the overall differences between aggregates and crushed material.

\section{Carbon mineralization as affected by aggregation} Considering all soils, ANOVA revealed a significant effect of aggregation only for the small fraction, whereas a significant impact of aggregate size cannot be found. For the RTM soils (wheat/grassland), aggregation showed a significant effect on the respiration rates when considering all samples $(P<0.001)$ and also when each fraction was tested separately $(P<0.001)$. For Chorin, aggregation showed a significant effect on the respiration rates when including all samples $(P<0.001)$ and for the small fraction $(P<0.001)$, but not for the large fraction. Samples from Steinkreuz showed a significant effect for only the fraction size $(P<0.001)$, but not for aggregation. For all other soils, the effects of aggregation and size were not significant $(P>0.05)$.

To illustrate the effect of aggregation, the differences between the cumulative carbon release from crushed material and intact aggregates as a function of incubation time are shown in Fig. 2. Particularly for RTM and Chorin, large differences were measured for nearly the entire incubation period. The largest slopes were found at the initial stage of the incubation experiment indicating the greatest differences between aggregates and crushed material. In other words, the protective effect was most efficient at the beginning of the incubation but remains effective during the whole incubation period at least for RTM and the small fraction 
Table 2. Mineralization rate constants, $k$, pool sizes, half-lives, $H L$, of the rapidly and slowly decaying components and percentage of mineralized carbon after 30 days of incubation for intact aggregates and corresponding crushed material ${ }^{a}$.

\begin{tabular}{|c|c|c|c|c|c|c|c|}
\hline \multirow{2}{*}{ Soil } & \multirow{2}{*}{$\frac{\text { Fraction }\left(\text { type }^{b}\right)}{\mathrm{mm}}$} & \multicolumn{2}{|l|}{$k_{1}^{c}$} & Labile pool & Stable pool & \multirow{2}{*}{$\frac{H L_{\text {lab }}}{\mathrm{d}}$} & \multirow{2}{*}{$\frac{H L_{\text {stab }}}{\mathrm{yr}}$} \\
\hline & & \multicolumn{2}{|c|}{$\mathrm{d}^{-1}$} & \multicolumn{2}{|c|}{$\%$} & & \\
\hline \multirow{2}{*}{ RTM (Wheat) } & $2-4(\mathrm{~A})$ & $2.25 \times 10^{-2}$ & $6.10 \times 10^{-5}$ & 1.06 & 98.94 & 30.8 & 31 \\
\hline & $2-4(\mathrm{C})$ & $2.71 \times 10^{-2}$ & $7.21 \times 10^{-5}$ & 1.69 & 98.31 & 25.5 & 26 \\
\hline \multirow{2}{*}{ RTM (Grassl.) } & $2-4(\mathrm{~A})$ & $3.13 \times 10^{-2}$ & $4.02 \times 10^{-5}$ & 0.46 & 99.54 & 22.1 & 47 \\
\hline & $2-4(\mathrm{C})$ & $3.50 \times 10^{-2}$ & $5.65 \times 10^{-5}$ & 0.68 & 99.32 & 19.8 & 34 \\
\hline \multirow{4}{*}{ Halle } & $2-4(\mathrm{~A})$ & $4.28 \times 10^{-2}$ & $1.58 \times 10^{-5}$ & 0.63 & 99.37 & 16.2 & 120 \\
\hline & $2-4(\mathrm{C})$ & $4.47 \times 10^{-2}$ & $1.71 \times 10^{-5}$ & 0.44 & 99.56 & 15.5 & 111 \\
\hline & $4-8(\mathrm{~A})$ & $3.18 \times 10^{-2}$ & $1.81 \times 10^{-5}$ & 0.38 & 99.62 & 21.8 & 105 \\
\hline & $4-8(\mathrm{C})$ & $2.99 \times 10^{-2}$ & $1.52 \times 10^{-5}$ & 0.34 & 99.66 & 23.2 & 125 \\
\hline \multirow{4}{*}{ Banteln } & $2-4(\mathrm{~A})$ & $1.20 \times 10^{-1}$ & $8.59 \times 10^{-5}$ & 0.55 & 99.45 & 5.8 & 22 \\
\hline & $2-4(\mathrm{C})$ & $1.66 \times 10^{-1}$ & $6.92 \times 10^{-5}$ & 0.59 & 99.41 & 4.2 & 27 \\
\hline & $4-8(\mathrm{~A})$ & $1.54 \times 10^{-1}$ & $7.24 \times 10^{-5}$ & 0.28 & 99.72 & 4.5 & 26 \\
\hline & $4-8(\mathrm{C})$ & $1.14 \times 10^{-1}$ & $6.22 \times 10^{-5}$ & 0.50 & 99.50 & 6.1 & 30 \\
\hline \multirow{4}{*}{ Chorin } & $2-4(\mathrm{~A})$ & $3.73 \times 10^{-2}$ & $6.85 \times 10^{-5}$ & 1.22 & 99.78 & 18.6 & 28 \\
\hline & $2-4(\mathrm{C})$ & $4.91 \times 10^{-2}$ & $6.52 \times 10^{-5}$ & 1.07 & 98.93 & 14.1 & 29 \\
\hline & $4-8(\mathrm{~A})$ & $3.68 \times 10^{-2}$ & $6.15 \times 10^{-5}$ & 1.32 & 98.68 & 18.8 & 31 \\
\hline & $4-8(\mathrm{C})$ & $4.12 \times 10^{-2}$ & $5.34 \times 10^{-5}$ & 0.94 & 99.06 & 16.8 & 36 \\
\hline \multirow{4}{*}{ Steinkreuz } & $2-4(\mathrm{~A})$ & $3.50 \times 10^{-1}$ & $1.09 \times 10^{-4}$ & 0.23 & 99.77 & 2.0 & 17 \\
\hline & $2-4(\mathrm{C})$ & $3.17 \times 10^{-1}$ & $9.21 \times 10^{-5}$ & 0.27 & 99.73 & 2.2 & 21 \\
\hline & $4-8(\mathrm{~A})$ & $2.20 \times 10^{-1}$ & $2.14 \times 10^{-4}$ & 0.33 & 99.67 & 3.2 & 9 \\
\hline & $4-8(\mathrm{C})$ & $1.81 \times 10^{-1}$ & $1.45 \times 10^{-4}$ & 0.41 & 99.59 & 3.8 & 13 \\
\hline \multirow{4}{*}{ Waldstein } & $2-4(\mathrm{~A})$ & $1.71 \times 10^{-1}$ & $2.93 \times 10^{-5}$ & 0.13 & 99.87 & 4.1 & 65 \\
\hline & $2-4(\mathrm{C})$ & $1.25 \times 10^{-1}$ & $3.90 \times 10^{-5}$ & 0.17 & 99.83 & 5.5 & 49 \\
\hline & $4-8(\mathrm{~A})$ & $1.32 \times 10^{-1}$ & $5.33 \times 10^{-5}$ & 0.10 & 99.90 & 5.3 & 36 \\
\hline & $4-8(\mathrm{C})$ & $8.75 \times 10^{-2}$ & $3.93 \times 10^{-5}$ & 0.17 & 99.83 & 7.9 & 48 \\
\hline
\end{tabular}

${ }^{a}$ Values are based on normalized data (carbon release per gram SOC); ${ }^{b} \mathrm{~A}$ : Aggregates; C: Crushed material; ${ }^{c}$ Mineralization rate constant of the labile pool; ${ }^{d}$ Mineralization rate constant of the stable pool.

of Chorin. For the large aggregates of Chorin after approximately 110 days of incubation the slightly negative slope indicated that from this time on the aggregates released more $\mathrm{CO}_{2}$ than the crushed material.

Figure 2 also shows the percentages of aggregate protected carbon, $C_{\text {prot }}$. It reveals that for RTM, Chorin, Waldstein (small fraction) and Banteln (large fraction) a considerable portion of SOC was protected within the aggregates. No protective effect of aggregation can be found for Halle, the small fraction from Banteln and the large fraction from Steinkreuz. Likewise, no clear trend could be observed for the protective capacity of the different size fractions investigated in this study.

\section{Discussion}

Lower respiration rates of intact aggregates as compared to corresponding crushed material may have two reasons. One possible explanation can be the restricted accessibility of water, nutrients and oxygen, resulting in lower microbial activity in the aggregate interior (Hartmann \& Simmeth 1990). Simulations of Augustin et al. (1995) suggested that the outer regions of aggregates are the most active and that there may be large aggre- gate centers without microbial growth. A further reason may be the reduced microbial accessibility of the SOM itself located in the aggregate interior (Tisdall \& Oades 1982) which becomes more accessible for microbial attack after crushing. This may allow a better physical contact between microorganisms and SOM (Gaillard et al. 1999).

Plante \& McGill (2002) showed that macroaggregate turnover resulted in the exposure of labile organic matter. For soils with higher respiration rates from the crushed material throughout the incubation experiment it can be assumed that a sufficient portion of labile SOM was still present (large labile pool). Conversely, for soils with higher rates from the crushed material at the beginning of the incubation and then from a certain time onward higher rates from the aggregates, it can be assumed that the pool of labile SOM was declining rapidly (small labile pool). A sufficient portion of the labile pool within the aggregates, however, was still present at this time resulting in higher respiration rates. The largest portions of the labile pool were found for RTM and Chorin supporting the assumption that the continuously higher rates from the crushed material may be related to a relatively large labile pool. The half-lives indicated that the labile pools of RTM and 

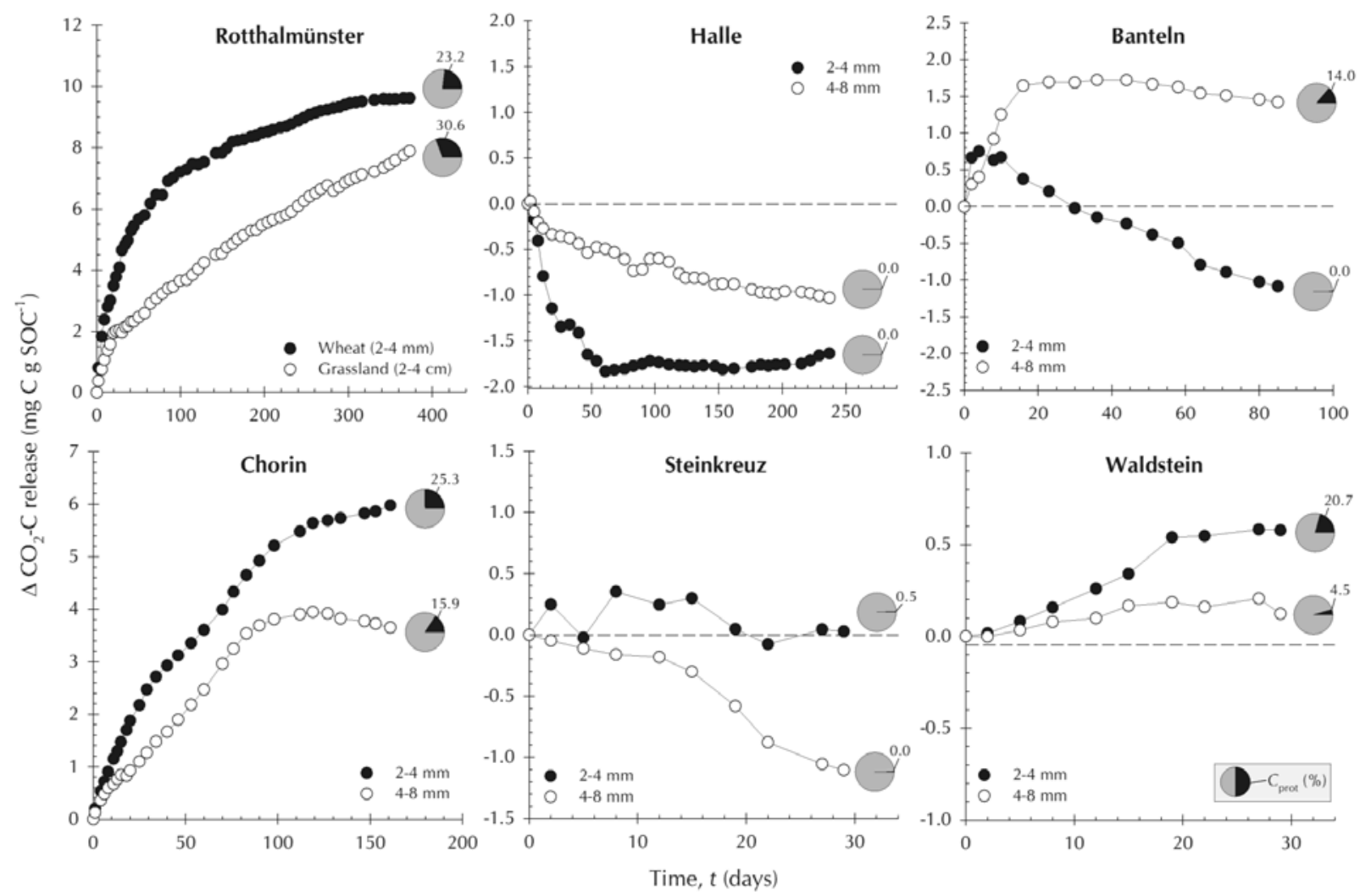

Fig. 2. Differences between the cumulative carbon release from crushed material and intact aggregates as functions of time, $t$. Also given is the percentage of aggregate protected carbon, $C_{\text {prot }}$.

Chorin were mineralized slowly, suggesting that a sufficient portion of labile SOM was present throughout the incubation experiments. These considerations suggest that the protective effect of aggregation will be temporary and depends on the relative proportions of the labile and stable pool.

However, the results obtained for the Halle soil with higher respiration rates from the aggregates throughout the experiment are not in line with this concept. Possibly, the low initial water contents (7.5 wt.\%) may allow a more favorable aeration within the aggregates in comparison to the crushed material. Lower respiration rates from crushed material compared to intact aggregates may also be explained by the destruction of existing diffusion and water pathways in macro- and mesopores.

We can conclude that for most of the soils investigated, the incubation experiments revealed a smaller $\mathrm{CO}_{2}$ release from intact aggregates as compared to corresponding crushed material. This is in line with the findings of various disruption studies demonstrating that SOM occluded in macroaggregates is physically protected from decomposition. However, statistically significant protective effects of aggregation (up to 30\%) for the entire incubation period could be found only for the soils from RTM and Chorin. From the fact that the significant effect of aggregation found for RTM and Chorin corresponded to very large portions of the labile pool, it can be concluded that the protective effect of aggregation depends on the relative proportions of the labile and stable pool, or in other words, protection due to aggregation seems to be effective primarily for soils with a comparatively large labile SOM pool regardless of use as arable or forest soil. For the other soils investigated the differences between aggregates and crushed material were too small to be statistically significant. We conclude that the general assumption that aggregation protects SOM from decomposition must be considered with caution and has to be checked for each single case because the processes of aggregate formation are too complex to expect a definite mechanism.

\section{Acknowledgements}

Financial support provided by the "Deutsche Forschungsgemeinschaft DFG" (Priority program "Soils as source and sink for $\mathrm{CO}_{2}$ - mechanisms and regulation of organic matter stabilization in soils", SPP1090, BA1359/5-1) for this study is greatly appreciated.

\section{References}

Augustin S., Jansen M., Priesack E. \& Beese F. 1995. Litter decomposition and matter transport in beds of soil aggregates, pp. 237-255. In: Hartge K.H. \& Stewart B.A. (eds), Soil structure - Its development and function. Adv. Soil Sci., CRC Press, Boca Raton.

Besnard E., Chenu C., Balesdent J., Puget P. \& Arrouays D. 1996. Fate of particulate organic matter in soil aggregates during cultivation. Eur. J. Soil Sci. 47: 495-503. 
Chenu C., Hassink J. \& Bloem J. 2001. Short-term changes in the spatial distribution of microorganisms in soil aggregates as affected by glucose addition. Biol. Fertil. Soils 34:349-356.

Elliott E.T. 1986. Aggregate structure and carbon, nitrogen, and phosphorus in native and cultivated soils. Soil Sci. Soc. Am. J. 50: $627-633$.

Gaillard V., Chenu C., Recous S. \& Richard G. 1999. Carbon, nitrogen and microbial gradients induced by plant residues decomposing in soil. Eur. J. Soil Sci. 50: 567-578.

Goebel M.-O., Bachmann J. \& Woche S.K. 2008. Modified technique to assess the wettability of soil aggregates: comparison with contact angles measured on crushed aggregates and bulk soil. Eur. J. Soil Sci. 59: 1241-1252.

Goebel M.-O., Bachmann J., Woche S.K \& Fischer W.R. 2005. Soil wettability, aggregate stability, and the decomposition of soil organic matter. Geoderma 128: 80-93.

Gupta V.V.S.R. \& Germida J.J. 1988. Distribution of microbial biomass and its activity in different soil aggregate size classes as affected by cultivation. Soil Biol. Biochem. 20: $777-786$.

Hartmann A. \& Simmeth I. 1990. Einfluss des Bodenwasserpotentials auf die Lokalisation mikrobieller Aktivität in Bodenaggregaten eines ariden Sandbodens. Mitt. Deutsch. Bodenkdl. Ges. 62: 39-42.

Hassink J. 1992. Effects of soil texture and structure on carbon and nitrogen mineralization in grassland soils. Biol. Fertil. Soils 14: 126-134.
John B., Yamashita T., Ludwig B. \& Flessa H. 2005. Storage of carbon in aggregate and density fractions of silty soils under different types of land use. Geoderma 128: $63-79$.

Plante A.F. \& McGill W.B. 2002. Intraseasonal soil macroaggregate dynamics in two contrasting field soils using labelled tracer spheres. Soil Sci. Soc. Am. J. 66:1285-1295.

Puget P., Angers D.A. \& Chenu C. 1999. Nature of carbohydrates associated with water-stable aggregates of two cultivated soils. Soil Biol. Biochem. 31: 55-63.

Puget P., Chenu C. \& Balesdent J. 1995. Total and young organic-matter distributions in aggregates of silty cultivated soils. Eur. J. Soil Sci. 46: 449-459.

Puget P., Chenu C. \& Balesdent J. 2000. Dynamics of soil organic matter associated with particle-size fractions of water-stable aggregates. Eur. J. Soil Sci. 51: 595-605.

Qualls R.G. \& Haines B.L. 1992. Biodegradability of dissolved organic matter in forest throughfall, soil solution, and stream water. Soil Sci. Soc. Am. J. 56: 578-586.

Sollins P., Homann P. \& Caldwell B.A. 1996. Stabilization and destabilization of soil organic matter: mechanisms and trols. Geoderma 74: 65-105.

Stevenson F.J. 1994. Humus chemistry: Genesis, composition, reaction, $2^{\text {nd }}$ ed. John Wiley and Sons, New York, 512 pp.

Tisdall J.M. \& Oades J.M. 1982. Organic matter and water-stable aggregates in soils. J. Soil Sci. 33: 141-163.

Received November 10, 2008 Accepted January 22, 2009 